\title{
OPTIMIZATION OF DIMENSIONS OF THE VALVE CHAMBER OF THE CONTROL VALVES OF STEAM TURBINE
}

\author{
L. Bednář ${ }^{*}$, L. Tajč ${ }^{* *}$, P. Kočárník ${ }^{* * *}$
}

\begin{abstract}
The definition of loss factors for the valve chamber and the control valve diffuser is stated. Optimal valve chamber dimensions are looked for to ensure minimal energy loss. Variants of different width and height of the chamber are tested. Various input piping modifications into the chamber are considered.
\end{abstract}

Keywords: steam turbine, control valve, valve chamber

\section{Introduction}

The control valves must ensure the mass flow of steam required to drive the turbine to the required power level. This is achieved by changing of the flow area and adjusting of the pressure ratio on the valve. With reduced machine performance, steam pressure reduction is required. This means that there is some pressure and energy loss in the valve. If the machine is working at full power, it is desirable that the resulting energy loss is minimized. Over the years, many design variants of the control valves were tested experimentally. Individual manufacturers adopted specific types of valve designs. The aim of this work is to evaluate by means of CFD studies and energy loss calculations whether there are certain reserves in the valve chamber which would lead to potential loss decrease in nominal turbine operation by means of both shape and dimensional adjustments. A characteristic design of the control valve is shown in Fig. 1. The valve chamber is connected via a saddle to the outlet diffuser. The basic dimensions of the parts are

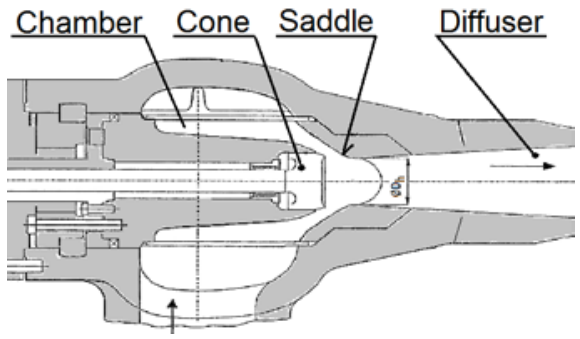

Fig. 1: Design of the control valve

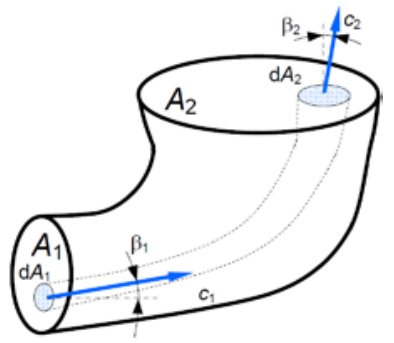

Fig. 2: Design of the valve chamber

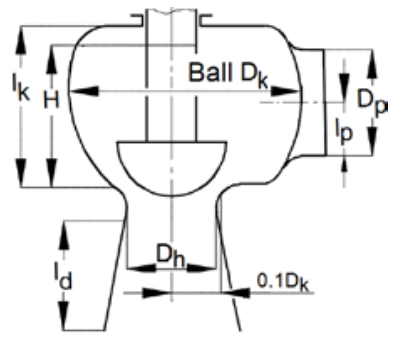

Fig. 3: Diagram of the basic geometric parameters of the valve chamber.

derived from the diameter of the diffuser neck $D_{h}$. This guarantees the geometric similarity of the valve for a number of mass flows. The energy loss is undoubtedly influenced by the shape of the bottom of the valve cone and the transition from the saddle to the diffuser. The design of these parts has an immediate influence on the stability of the flow and on the occurrence of pressure pulsations at the partial load of the turbine. The main criterion for shaping of these parts is the operational reliability of the valve. The valve chamber can be checked for its optimal dimensions in terms of its width and height. The shape of the inlet pipe can be assessed. The calculations also enable the share of the loss in the valve chamber and the total energy loss on the valve to be determined.

\footnotetext{
* Ing. Lukáš Bednáŕ: Doosan Škoda Power s. r. o., Tylova 1/57 30128 Plzeň; CZ, lukas.bednar@doosan.com

** Ing. Ladislav Tajč, CSc.: Doosan Škoda Power s. r. o., Tylova 1/57 30128 Plzeň; CZ, ladislav.tajc@doosan.com

*** Ing. Petr Kočárník, PhD.: ČVUT Praha, Technická 2, A3-516a, 16627 Praha 6 - Dejvice; CZ, kocarnik@fel.cvut.cz
} 


\section{Definition of loss factor}

The general case of the flow channel, assuming an uneven distribution of velocity and direction of velocity in the inlet and outlet cross section, is indicated in Fig. 2. For the steady flow of incompressible fluid of density $\rho$ the elementary mass flow can be expressed $d m \cdot$ with a cross section $d A$

$$
d \dot{m}=\rho c_{1} \cos \beta_{1} d A_{1}=\rho c_{2} \cos \beta_{2} d A_{2} .
$$

This corresponds to elementary flows of kinetic and compressive energy

$$
d \dot{E}_{k}=\frac{1}{2} c^{2} d \dot{m}=\frac{\rho}{2} c^{3} \cos \beta d A ; d E_{p}=\frac{p}{\rho} d \dot{m}=p c \cos \beta d A .
$$

We can express the exact energy flow balance by considering the loss coefficient related to the input kinetic energy $\zeta=E_{Z} / E_{k 1}$ as follows

$$
\dot{E}_{k 1}+\dot{E}_{p 1}=\dot{E}_{k 2}+\dot{E}_{p 2}+\zeta_{E} \dot{E}_{k 1} .
$$

In the balance, we can also consider efficiency in the form of energy $\eta$, defined as the ratio of total output and input energy

$$
\eta\left(\dot{E}_{k 1}+\dot{E}_{p 1}\right)=\dot{E}_{k 2}+\dot{E}_{p 2} .
$$

The loss coefficient in the valve chamber (the inlet-neck segment) can be expressed as

$$
\zeta_{\text {chamber }}=\frac{\dot{E}_{\text {kinlet }}+\dot{E}_{\text {pinlet }}+\dot{E}_{\text {kneck }}+\dot{E}_{\text {pneck }}}{\dot{E}_{\text {kinlet }}} \text {. }
$$

We will get the power of mechanical energy transmission in the chamber

$$
\eta_{\text {chamber }}=\frac{\dot{E}_{\text {kneck }}+\dot{E}_{\text {pneck }}}{\dot{E}_{\text {kinlet }}+\dot{E}_{\text {pinlet }}} \text {. }
$$

Similarly, the loss factor and efficiency for the diffuser are expressed

$$
\zeta_{\text {dif }}=\frac{\dot{E}_{\text {kneck }}+\dot{E}_{\text {pneck }}-\dot{E}_{\text {koutlet }}-\dot{E}_{\text {poutlet }}}{\dot{E}_{\text {kinlet }}} ; \eta_{\text {dif }}=\frac{\dot{E}_{\text {koutlet }}+\dot{E}_{\text {poutlet }}}{\dot{E}_{\text {kneck }}+\dot{E}_{\text {pneck }}} .
$$

For the whole valve (input - output section) we get

$$
\zeta_{\text {valve }}=\zeta_{\text {chamber }}+\zeta_{\text {dif }} ; \eta_{\text {valve }}=\eta_{\text {chamber }} \cdot \eta_{\text {dif }} \text {. }
$$

As other parameters for assessing the quality of the flow channel adjustments can be used

a) The mean value of the components of velocity $\overline{c_{a x}}, \overline{c_{\tan }}, \overline{c_{\text {rad }}}$ ) and the mean value of pressure $\bar{p}$.

b) The mean kinetic and pressure energy flow $\overline{E_{\text {ktan }}}$ a $\overline{E_{\text {prad }}}$.

c) Uncertainty of distribution of the axial component of velocity in the tangential and radial direction, expressed as the mean quadratic error of distribution $\Delta c_{a x i}^{*}$ in the given direction.

The computational study is solved by using the Fluent 6.2 programme. As a model of turbulence $\mathrm{k}-\omega$ is chosen. The number of mesh elements is in the range (1.5 to 2.5$) \cdot 10^{6}$. In order to eliminate changes in bow, saddle and diffuser flow, the volume flow of the valve in all variants is equal to $1.272 \mathrm{~m}^{3} \mathrm{~s}^{-1}$. For most variants, the mean axial velocity value corresponds to $c_{\max }=50 \mathrm{~ms}^{-1}$.

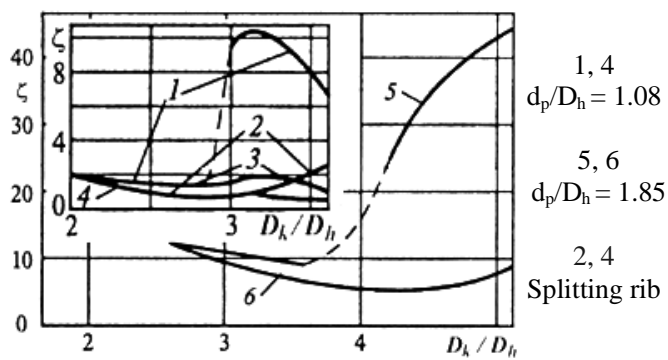

Fig. 4: Dependence of the loss coefficient on the relative diameter

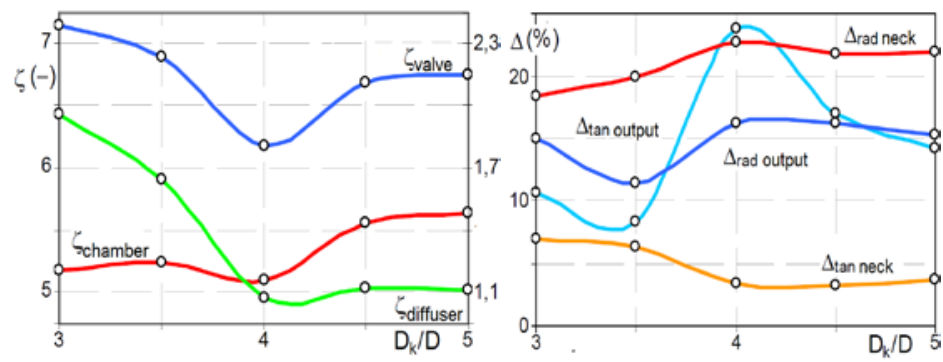

Fig. 5: Flows of loss factors and uneven distribution of flows 


\section{Modification of valve chamber}

The valve chamber is generally composed of a spherical section with a diameter of the sphere $D_{k}$ and the height of the layer $l_{k}$. The flow diagram of the valve chamber is shown in Figure 3 . The flow in the valve chamber depends on the relative ratio of some parameters. As it is demonstrated by the calculations, which was also proven experimentally, a positive effect on the valve discharge against the valve chamber was shown (Bednar at al., 2016). It also depends on the steam velocity in the inlet pipe. The transition to the valve chamber relates to the loss due to the step change of the cross section. Undoubtedly, the energy loss depends on the choice of the chamber diameter and therefore on the $\mathrm{D}_{k} / \mathrm{D}_{\mathrm{h}}$ ratio, and on bonds such as $d_{p} / D_{h}, H / l_{k}, l_{p} / l_{k}$ and the shape of the connection of the inlet pipe to the valve chamber.

\section{Modification of valve chamber diameter}

Based on the findings from the Russian sources (Kamirin, 1969 and Kamirin et al., 1959), it is known that under certain circumstances, a circulatory flow associated with a significant increase in loss can occur in the valve chamber. As shown in the graph in Fig. 4, there is a certain connection with the dimensions of the inlet pipe. However, the decisive cause of this circulatory flow is not known. A computational study showed the impact of the $D_{k}$ diameter on the energy loss range. The results of the calculations are depicted in Figure 5. It is obvious that the minimum value of the loss coefficient corresponds to the ratio of $D_{k} / D_{h}=4$. For smaller values, the loss in the diffuser is greatly increased, while in the higher values the loss in the valve chamber increases. Changing the ratio significantly affects the value of the mean unevenness of the flow expansion in the tangential direction in the output cross section. The calculations do not confirm the formation of the circulatory flow in the valve chamber.
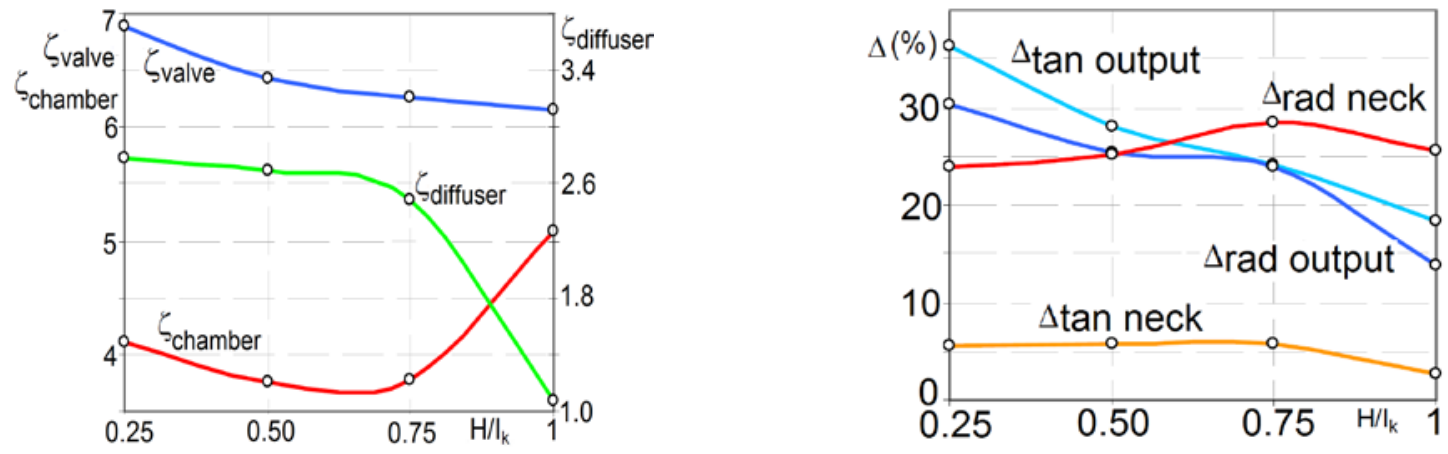

Fig. 6: Flows of loss factors and uneven distribution of pressure

\section{Modification of the chamber by cutting}

Another modification of the shape of the valve chamber lies in the oblique cutting of the upper part thereof. The ratio of the smallest and largest chamber height $\mathrm{H} / \mathrm{l}_{\mathrm{k}}$ is chosen as the dimensionless parameter of this cut. The course of the loss coefficients and the unequal distribution of the flow in the cross-sections as a function of $\mathrm{H} / \mathrm{l}_{\mathrm{k}}$ are shown in Fig. 6. It follows from the course that with a slight decrease in the ratio to approx. $\mathrm{H} / \mathrm{l}_{\mathrm{k}}=0,7$ there is a significant reduction in loss in the chamber but the loss in the diffusor increases. Further decreasing the $\mathrm{H} / \mathrm{l}_{\mathrm{k}}$ ratio only increases the values of both coefficients. Therefore, the overall loss factor has a negative impact on the cut of the chamber. From the distribution point of view of the flow, the oblique cut of the chamber deteriorates in particular the uneven distribution in the output cross section.

\section{Modification of valve chamber inlet}

One of the possible adjustments of the inlet section of the valve is the introduction of two tangential inputs. According to the published data (Kamirin et al., 1959), there should be a noticeable reduction in the pressure loss in the chamber compared to the version with one central entry only. The design of the model is shown in Fig. 7. The computational variant of the valve with two tangential diffuser inputs is shown in Fig. 8. The input cross section of each input is identical. To maintain the same volume flow on the two-port valve, the average input speed is half the $25 \mathrm{~m} / \mathrm{s}$. However, this complicates the evaluation of the loss factor which is related to the input of kinetic energy. Therefore, the loss coefficient is multiplied by the correction coefficient (approx. 1/4) resulting from the ratio of the total input of kinetic energy to the input of kinetic energy in the reference variant. 


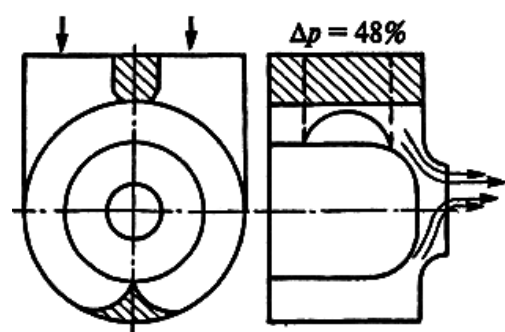

Fig. 7: Experimental model -2 tangential inputs

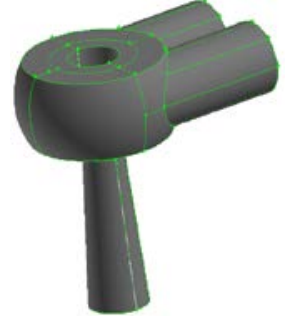

Fig. 8: 2 tangential inputs
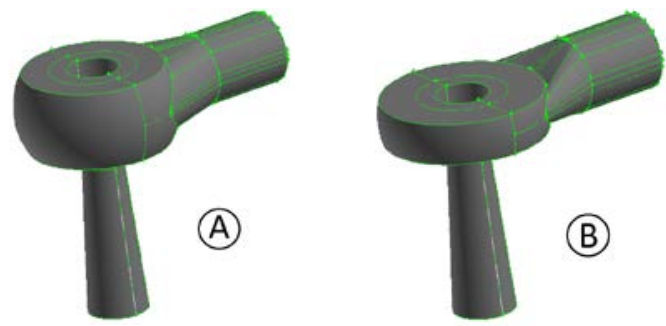

Fig. 9: Inlet modification by diffuser

Obviously, in the two-input variant, the inlet piping must be divided into two separate inlets somewhere in front of the valve. This causes additional energy dissipation which is not included in the calculation. Therefore, a variant with a short input diffuser - version A in Fig. 9 - was prepared for comparison purposes. The diffuser output is twice the size of the input. The angle of the cone is too large to avoid breaking of the flow. Therefore, as a further variant, the diffuser (design B in Fig. 9) is deformed so that its cross section does not change and the flow in it is better transferred into two tangential directions similarly to the two inputs. The height of the valve chamber was reduced by half. The comparison of the loss coefficient size and the uneven flow distribution in the variants examined is depicted in Figure 10. In all variants, the total loss factor is greater than in the case of the original single input configuration. Expectations according to the simplified model in Figure 7 are not fulfilled.
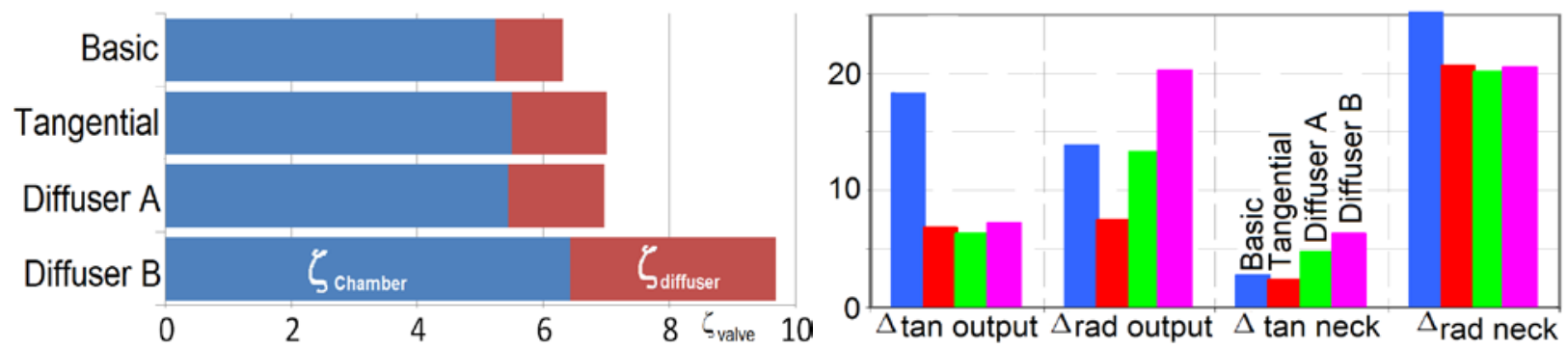

Fig. 10: Loss factor and uneven distribution of pressure

\section{Conclusions}

It is clear from the modifications made to the shape of the valve chamber that the optimization of its shape in terms of the loss coefficient is very sensitive and the overall impact of modification on the reduction of the loss coefficient is small. - Calculations have shown that two tangential inputs or input diffusers do not lead to a reduction in the overall loss factor as they increase the dissipation in the output diffuser. - The impact of the cutting of the top wall of the chamber is also negative, the loss in the chamber decreases but the loss in the diffuser output is significantly increased. • From all the calculations made it can be concluded generally that basically any positive change in the loss coefficient (i.e. its reduction) in the valve chamber is negatively reflected in the increase of the loss coefficient in the diffuser. - The original spherical shape of the valve chamber is considerably close to the optimum in terms of the value of the loss coefficient. The main parameter affecting total loss in the open valve is in particular the diameter of the chamber.

\section{References}

Bednář, L., Tajč, L., Miczán, M., Hoznedl, M., Kočárník, P. and Jirků, S. (2016) The impact of shape adjustments of a valve chamber on losses in the control valve of the steam turbine. Engineering Mechanics 2016, IT AS CR, Prague, pp. 54-57.

Kamyrin, B. I. (1969) O kharaktere dvizheniy para v klapannoy korobke, Energomashinostroyenie, № 11, pp. 38-41.

Kamyrin, B. I. and Rebzin, B. S. (1959) Snizhenie poter' davleniya v reguliruyushchikh klapanakh turbin vysokovo davleniya, Energomashinostroyenie, № 1 .

Kočárník, P. (2011) Výpočty tvaru ventilové komory při použití dvou tečných vstupů, vliv vyosení výstupu a přepážky, výpočty reálné geometrie ventilu, ČVUT Praha, výzkumná zpráva č. 43/100018/13114. 